\title{
Effect of Melatonin Injected into the Third Ventricle on Growth Hormone Secretion in Holstein Steers
}

\author{
Etsuko KASUYA ${ }^{1)}$, Shiro KUSHIBIKI'), Madoka SUTOH'), Toshiyuki SAITO'), Shuichi ITO ${ }^{1)}$, Ken-ichi YAYOU ${ }^{1)}$, \\ Ryosuke SAKUMOTO ${ }^{1)}$ and Koichi HODATE ${ }^{3)}$ \\ ${ }^{1)}$ Department of Physiology and Genetic Regulation, National Institute of Agrobiological Sciences, Tsukuba, Ibaraki 305-8602, \\ ${ }^{2}$ Department of Animal Physiology and Nutrition, National Institute of Livestock and Grassland Science, Tsukuba, Ibaraki 305-0901 and \\ ${ }^{3)}$ School of Veterinary Medicine and Animal Sciences, Kitasato University, Towada, Aomori 034-8628, Japan
}

(Received 30 January 2006/Accepted 15 June 2006)

\begin{abstract}
The effects of melatonin (MEL) injection into the third ventricle (3V) on growth hormone (GH) secretion were investigated in conscious Holstein steers. A stainless steel cannula was stereotaxically implanted in the $3 \mathrm{~V}$ based on the ventriculogram. In Exp. 1, three doses of MEL $(100,300$ or $600 \mu \mathrm{g})$ were injected into the $3 \mathrm{~V}$ through the cannula and the GH concentration after the injection was determined. In Exp. 2, intracerebroventricular (icv) and intravenous (iv) injections of MEL (100 $\mu \mathrm{g}$ ) and GH-releasing hormone (GHRH; $0.25 \mu \mathrm{g} / \mathrm{kg}$ body weight), respectively, were performed simultaneously to examine the effect of MEL on GHRH-induced GH release. The icv injection of MEL significantly stimulated GH release at $100 \mu \mathrm{g}$. The increase in GH concentrations by $100 \mu \mathrm{g}$ of MEL was persistent. Intravenous injection of GHRH dramatically increased GH release. The injection of MEL did not alter GHRH-induced GH release. These results suggest that MEL stimulates GH secretion possibly through the hypothalamus in cattle.

KEY WORDS: cattle, melatonin, somatotropic axis, stereotaxic, third ventricle.
\end{abstract}

J. Vet. Med. Sci. 68(10): 1075-1080, 2006

Growth hormone $(\mathrm{GH})$ is a very important factor for livestock production [6]. GH-releasing hormone (GHRH) and somatostatin (SS) from the hypothalamus are primary factors controlling $\mathrm{GH}$ secretion in mammals. In addition to GHRH and SS, many neuromodulators have been considered to be involved in GH release regulation in many species. Although the central regulatory mechanism of $\mathrm{GH}$ secretion has been studied in sheep using hypophyseal portal blood sampling technique [4], such information is not well obtained in cattle.

The evidences have shown the possibility that melatonin (MEL) from the pineal gland is one of those factors controlling GH secretion; however, the exact effect of MEL on GH secretion is controversial. For example, in humans it was reported that MEL induced an increase in GH levels [27, 29]; however, other groups obtained no effects of MEL on GH secretion $[13,31]$. The intramuscular injection of MEL decreased GH secretion in prepubertal boys and the same dose of MEL increased GH level in some pubertal subjects [17]. In vitro experiments showed that MEL reduced GH secretion from rat pituitary cells [8]. These variations of the effects of MEL on GH secretion could be caused by the differences in the experimental and physiological conditions, and there might be inter-species differences regarding the role of MEL in the regulation of GH secretion.

The purpose of the present study was to determine the role of MEL in the regulatory system of GH secretion in cattle. Since MEL has been reported to stimulate GH release via the hypothalamus [23, 29], the technique for the direct injection of MEL into the third ventricle (3V) at three doses $(100,300$ and $600 \mu \mathrm{g})$ was used. We also assessed whether MEL affects GHRH-induced GH release to reveal the involvement of the hypothalamus in GH secretion modu- lated by MEL.

\section{MATERIALS AND METHODS}

Animals: Eleven Holstein steers ( 7 to 8 mo old at the time of surgery) raised on the farm of the National Institute of Livestock and Grassland Science (Tsukuba, Japan) were used in the present study. The animals were fed hay and concentrate twice a day at 0830 and 1500 and allowed water ad libitum. Each animal was tied with a stanchion stall and its rectal temperature was monitored just before each feeding every day. The surgical and experimental procedures used on the animals were approved by the Institute Committee for Animal Use and Care at the National Institute of Agrobiological Sciences.

Stereotaxic surgery: Animals were deprived of food on the day before brain surgery. After the animal was sedated with an intramuscular injection of xylazine hydrochloride (Ceractal, Bayer Japan, Tokyo Japan, $112 \mathrm{mg}$ /animal at the maximal level and actual dose was depending on the animal's condition), tracheal intubation was performed. Then, inhalational general anesthesia was initiated with isoflurane (Isoflu, Abbott Laboratories, North Chicago, IL, U.S.A.) and nitrogen monoxide $(0.5 \mathrm{l} / \mathrm{min})$. The detail design of the stereotaxic apparatus for cattle [24] was already described. The cerebral ventriculography was performed based on the previous report [12] with small modification. The head of the animal was mounted on the apparatus properly, and the surface of the skull was exposed. Then a small hole was created on the skull to insert a spinal needle (18 gauge, Terumo, Tokyo, Japan) into the lateral ventricle of the brain. Radioopaque dye (Iopamiron 300, Nihon-Schering, Osaka, Japan) was injected into the lateral ventricle through the needle and 


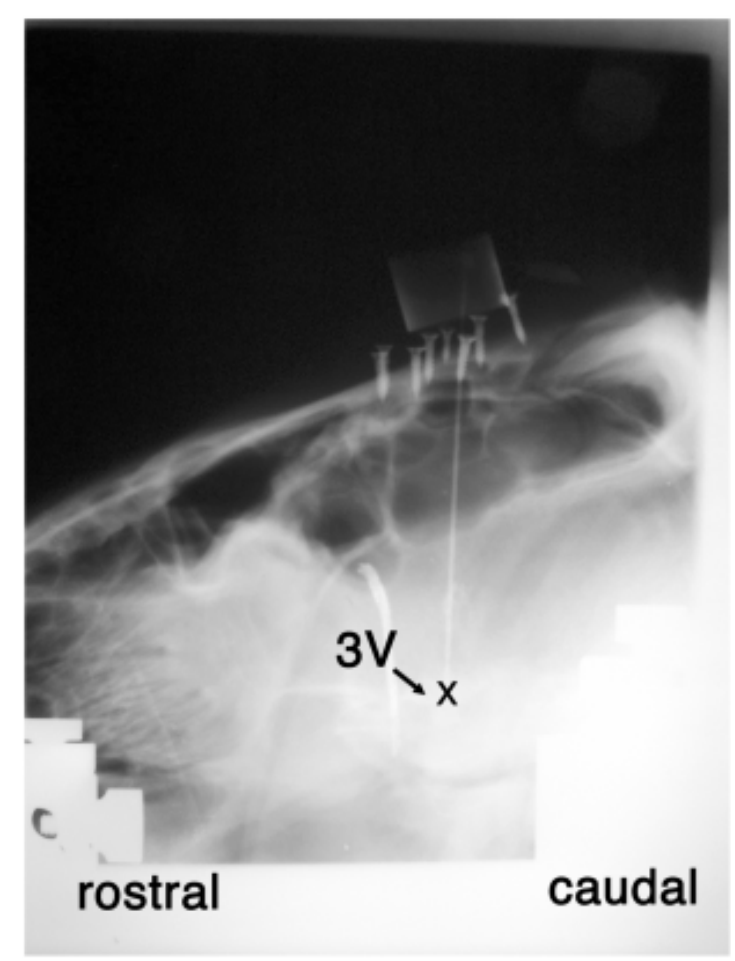

Fig. 1. Representative lateral ventriculogram obtained from the stereotaxic surgery in Holstein steers. The letter " $X$ " indicates the position of the tip of implanted cannula. Note that the cannula was exactly inserted into the third ventricle $(3 \mathrm{~V})$.

$\mathrm{X}$-ray pictures were taken to visualize the $3 \mathrm{~V}$. According to those images, the exact position of the third ventricle was expressed with 3-dimensional coordinates of the apparatus and a guide cannula (18 gauge, Eicom, Kyoto, Japan) was inserted until the tip of the cannula reached the $3 \mathrm{~V}$. The target point of the implantation is shown in Fig. 1. The cannula was fixed with dental acrylic resin (ADFA, Shofu Inc., Kyoto, Japan) and a stylet was inserted into the guide cannula until the day of the experiment. To recover the animal from anesthesia, an intramuscular injection of atipamezole hydrochloride (Antisedan, Meiji Seika Kaisha, Ltd., Tokyo, Japan) was performed. The steer was transferred from the surgery room into the experimental stall after the awakening and given approximately 10 days for its recovery.

Experiment 1: The effects of the intracerebroventricular injection of MEL on the secretion of GH in Holstein steers.

In Exp. 1, the effect of a single intracerebroventricular (icv) injection of MEL at three doses on the basal GH secretion was investigated. The animals were kept in individual indoor stalls under natural lighting conditions $(10-13 \mathrm{hr}$ of light) through the window. Mean room temperature was $20.9 \pm 0.6^{\circ} \mathrm{C}$. The animals were well accustomed to the experimental conditions and researchers by the day of the experiment, such that the experimental procedures did not disturb the physiological conditions of the animal. An ind- welling catheter was inserted into the external jugular vein at least $20 \mathrm{hr}$ before the initiation of the experiment. At 1030, the animal was lightly restrained with a rope and the remaining feed was removed. Melatonin (Sigma, St. Louis, MO, U.S.A.; $100 \mu \mathrm{g}$ or $300 \mu \mathrm{g}$ in $200 \mu \mathrm{l} 1 \%$ ethanol- $0.9 \%$ $\mathrm{NaCl})$ or vehicle $(400 \mu l 1 \%$ ethanol- $0.9 \% \mathrm{NaCl})$ was injected into the $3 \mathrm{~V}$ via the implanted cannula at $1200(0$ min). For the dose of $600 \mu \mathrm{g}, 400 \mu \mathrm{l}$ of "300 $\mu \mathrm{g}$ solution" was injected. The icv injection was performed at the rate of $200 \mu \mathrm{l} / 30 \mathrm{sec}$. Blood samples were drawn at $-60,-40,-20$, $2,10,20,30,40,50,60,80,100,120,140,160$ and $180 \mathrm{~min}$ after the icv injection. Each treatment (vehicle, 100, 300 or $600 \mu \mathrm{g}$ of MEL) was randomized in each animal. Since the injection took 30 to $60 \mathrm{~s}$, only the drawing immediately after the injection was performed with a 2-min delay. The blood $(10 \mathrm{~m} l)$ was collected into the heparinized tubes and immediately put on ice. The plasma was separated by centrifugation $\left(1500 \times \mathrm{g}, 4^{\circ} \mathrm{C}, 30 \mathrm{~min}\right)$ after each experiment was finished and stored at $-20^{\circ} \mathrm{C}$ until assayed.

Experiment 2: The effect of the intracerebroventricular injection of MEL on GHRH-induced GH secretion in Holstein steers.

In Exp. 2, the effects of icv injection of MEL on GHRHinduced GH secretion were investigated. This series of experiments was performed in the experimental room without windows under the artificial lighting (0600-1800; light), room temperature $\left(20^{\circ} \mathrm{C}\right)$ and humidity $(60 \%)$ conditions. The time course and procedure of blood drawing were the same as the ones of Exp. 1. Based on the result from Exp. 1, MEL $(100 \mu \mathrm{g})$ was injected into the $3 \mathrm{~V}$ through the implanted cannula at $0 \mathrm{~min}$. Bovine GHRH (generously provided by Prof. Shin-ichi Ohashi, Kanazawa Institute of Technology, Japan; $0.25 \mu \mathrm{g} / \mathrm{kg}$ body weight) diluted with sterilized $0.9 \% \mathrm{NaCl}$ was injected intravenously, immediately before the blood sample $(10 \mathrm{~m} l)$ was taken at $2 \mathrm{~min}$ after the icv injection. As a control for GHRH injection, $0.9 \% \mathrm{NaCl}$ alone was administered intravenously. The data obtained from Exp. 1 was used for further comparison between MEL $(100 \mu \mathrm{g})$ alone and GHRH with the MEL group.

Hormone assays and statistical analysis: Plasma GH concentrations were determined by double-antibody radioimmunoassay (RIA) based on the method of Johke [10]. The intra- and inter- assay CV was 6.3 and $9.4 \%$, respectively. The assay sensitivity was $1.25 \mathrm{ng} / \mathrm{ml}$. Plasma MEL concentrations were measured using a commercially available RIA kit (Bühlmann Laboratories, Schönenbuch, Switzerland) following the manufacturer's protocol. The intra- and interassay CV was 7.2 and $11.0 \%$, respectively. The assay sensitivity was $0.5 \mathrm{pg} / \mathrm{ml}$.

As an index of the amount of $\mathrm{GH}$ released in response to each agent, the area under the GH response curve (AUC) for $170 \mathrm{~min}$ after the injection was calculated. Data were represented as the mean \pm standard error. The effects of MEL and GHRH on mean levels and AUCs of MEL and GH were determined using 1-way ANOVA, followed by post hoc analysis with the Tukey's test to compare the difference 
between the values of control and treated groups. Statistical significance was attained at $\mathrm{P}<0.05$.

Macroscopic confirmation of the injection point: At the termination of experiments, the animal was euthanized by the injection of an overdose of sodium pentobarbital (Nembutal, Dainippon Pharmaceutical Co., Ltd., Osaka, Japan). Approximately $100 \mu l$ of brilliant blue solution was slowly injected through the implanted cannula just after the death of the animal to dye and visualize the injection point. When the cannula was properly implanted in the $3 \mathrm{~V}$, the inside wall of the $3 \mathrm{~V}$ should have been stained blue. In the present study, the cannula was appropriately implanted in all cases, as confirmed macroscopically by this method.

\section{RESULTS}

Experiment 1: The effects of intracerebroventricular injection of MEL on the secretion of GH in Holstein steers.

The changes in plasma MEL concentrations after the icv injection of MEL are shown in Fig. 2. Plasma MEL levels were significantly increased immediately after the MEL injection at three doses applied $(100,300$ or $600 \mu \mathrm{g})$. The increase was observed in the plasma taken at $2 \mathrm{~min}$ after the injection and lasted until 120 or $180 \mathrm{~min}$ after the injection of 300 or $600 \mu \mathrm{g}$ of MEL, respectively, compared to the corresponding value of the control group. The some values of MEL between 2 and 50 min or 2 and 80 min after the injection of 300 or $600 \mu \mathrm{g}$ of MEL, respectively, were higher than those of the assay limitation, such that the actual MEL peak levels by 300 and $600 \mu \mathrm{g}$ injections were not obtained in the present study. The injection of MEL at $100 \mu \mathrm{g}$ induced smaller increase in MEL concentrations than that at 300 and $600 \mu \mathrm{g}$. The peak level of plasma MEL was observed at $10 \mathrm{~min}$ after the icv injection and the significant increase in MEL level lasted until $80 \mathrm{~min}$ after the injection. On the other hand, the icv injection of vehicle ( $1 \%$ ethanol) did not cause any changes in the MEL concentration.

Figure 3A shows the changes in plasma GH concentrations after the icv injection of MEL at 3 doses. Although MEL injection tended to increase GH secretion at all doses examined, the significant increase was observed only in 100 $\mu \mathrm{g}$ - treated group when the comparison was performed between control and MEL-treated group. The GH levels at 80 and $100 \mathrm{~min}$ after the icv injection of MEL $(100 \mu \mathrm{g})$ were higher than those of control group $(\mathrm{P}<0.05)$. The tendency of the increase in $\mathrm{GH}$ concentrations was started just after the icv injection of MEL (100 $\mu \mathrm{g})$ and it lasted during the experimental period. The injection of the vehicle did not alter GH secretion. Figure 3B shows the AUC for $170 \mathrm{~min}$ after each treatment. The AUC for $100 \mu \mathrm{g}$ of MEL-treated group was significantly $(\mathrm{P}<0.01)$ greater than that for controls.

Experiment 2: the effects of the intracerebroventricular injection of MEL on GHRH-induced GH secretion in Holstein steers

Figure 4A shows the changes in plasma GH concentrations after the iv injection of GHRH $(0.25 \mu \mathrm{g} / \mathrm{kg}$ body

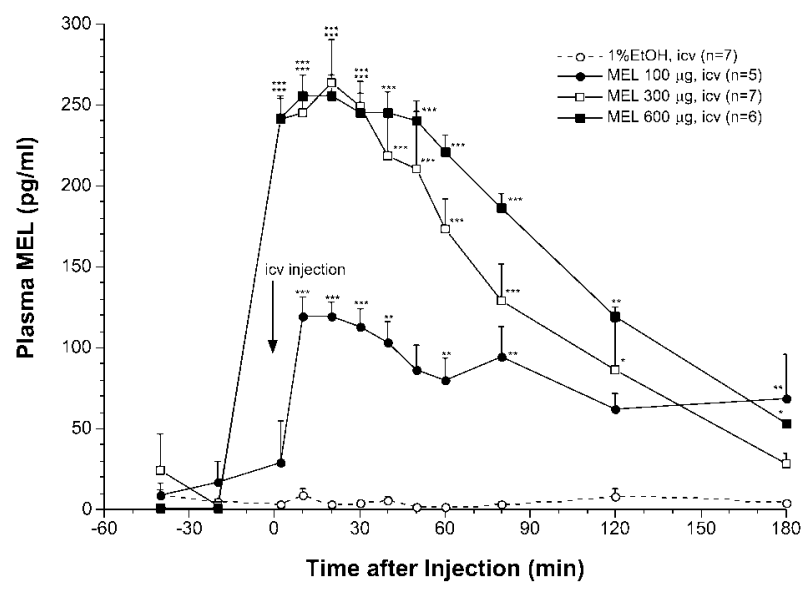

Fig. 2. Changes in the plasma melatonin (MEL) concentration after intracerebroventricular (icv) injection of MEL (100; closed circles, 300; open squares or $600 \mu \mathrm{g}$; closed squares) or $1 \%$ ethanol (EtOH, open circles with dotted line). An arrow shows the time of the injection. Each value is expressed as the mean + standard error. The asterisks show the statistical significance compared to the corresponding value of the control ( $1 \%$ ethanol) group (***; $\mathrm{P}<0.001, * * ; \mathrm{P}<0.01, * ; \mathrm{P}<0.05$ ).

weight) alone or in combination with the icv injection of MEL $(100 \mu \mathrm{g})$. The injection of GHRH induced a significant increase in GH. The level of GH began to increase just after the injection of GHRH. The GH level reached the peak at $18 \mathrm{~min}$ after the iv injection, then it returned to its basal level (mean value of pre-injection period) $80 \mathrm{~min}$ after the injection. When GHRH was injected with icv MEL, it also stimulated GH secretion (Fig. 4). There was no significant difference between responses of GH to GHRH alone and in combination with MEL. Figure 4B shows the AUC for 170 min after each treatment. Both AUCs for GHRH alone and GHRH with MEL were significantly greater than that for control group $(\mathrm{P}<0.01)$. There was no significant difference between the AUCs for GHRH alone and GHRH with MEL.

\section{DISCUSSION}

The present study demonstrated that a single injection of MEL into the $3 \mathrm{~V}$ induced an increase in basal GH concentrations in Holstein steers (Fig. 3). The result suggests the possibility that MEL is involved in the regulation of $\mathrm{GH}$ secretion from the anterior pituitary in cattle. The effects of MEL on GH secretion are not consistent and are still controversial at present. For example, the stimulatory effect of MEL on GH secretion was observed when MEL was administered in the morning $[27,29,30]$ when endogenous MEL levels are low [13]. The administration of MEL had no effect on GH secretion when it was given at 1700 [13]. The inconsistency observed in humans may have occurred due to the difference of the administration method or physiological condition. In the present study MEL was injected at noon, when the endogenous MEL levels were low in both the 

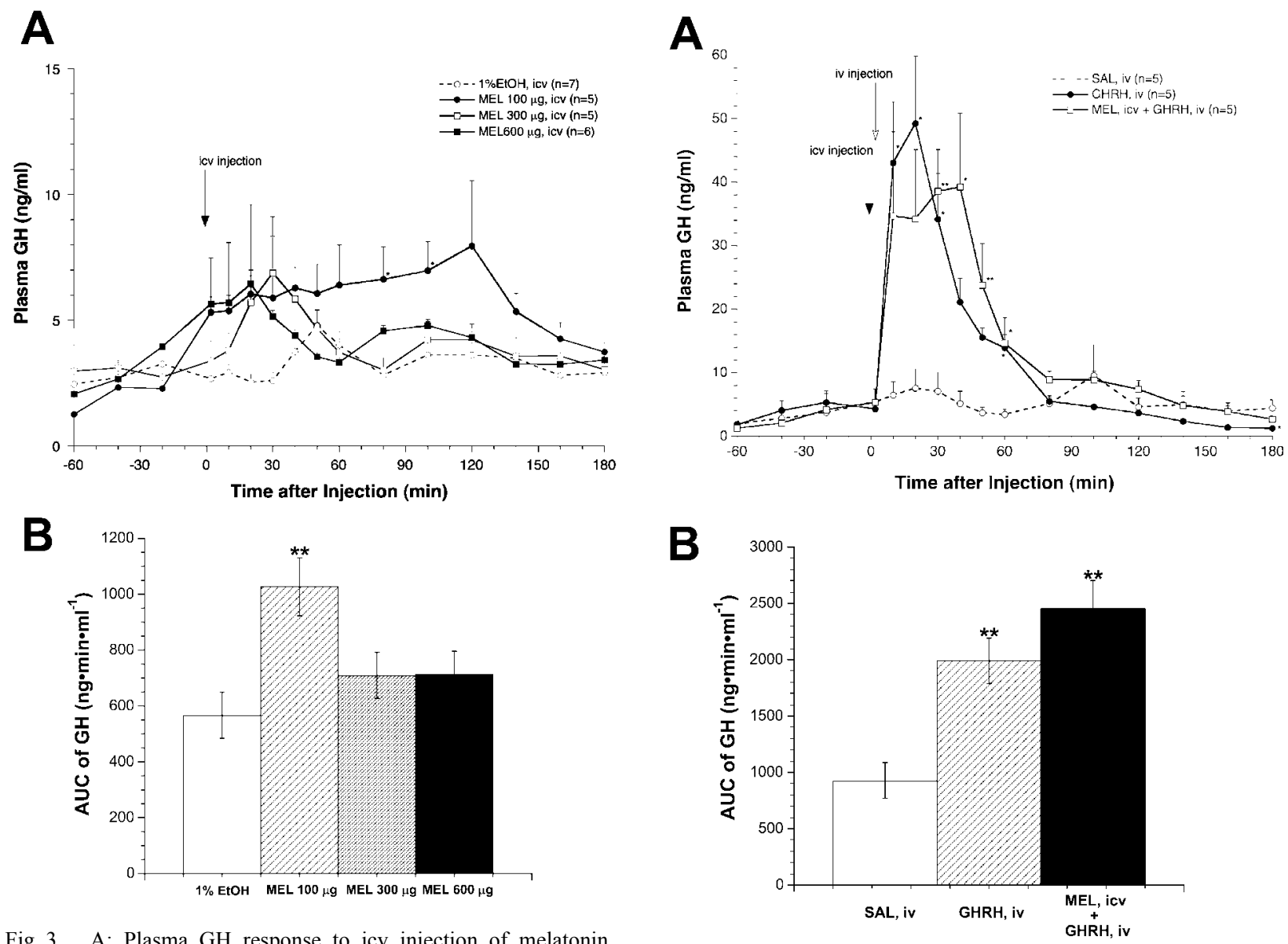

Fig. 3. A: Plasma GH response to icv injection of melatonin (MEL, 100; closed circles, 300; open squares or $600 \mu \mathrm{g}$; closed squares) or $1 \%$ ethanol (EtOH, open circles with dotted line). An arrow shows the time of the injection. B: Area under GH response curve (AUC) after the icv injection. Each value is expressed as the mean \pm standard errors. The asterisks show the statistical significance compared to the corresponding value of the control ( $1 \%$ ethanol) group $(* * ; \mathrm{P}<0.01, * ; \mathrm{P}<0.05)$.

plasma and the cerebrospinal fluid (CSF) in calves [9]. When MEL was injected at $100 \mu \mathrm{g}$ into the $3 \mathrm{~V}$, plasma MEL concentrations reached approximately $130 \mathrm{pg} / \mathrm{m} l$ (Fig. 2). This MEL level is similar to that observed during night time in calves [9]. Therefore, the injection method and doses are considered to be appropriate to evaluate the role of MEL in the central regulatory mechanism of GH secretion.

In order to understand the mechanism underlying MELinduced GH release, the effect of MEL on GHRH-induced GH release in steers was investigated (Exp. 2). Since physiological increase in MEL concentrations was obtained in $100 \mu \mathrm{g}$ of MEL injected steers in Exp. 1, we chose $100 \mu \mathrm{g}$ of MEL for the icv injection for Exp. 2. Although the present result showed that intravenous injection of GHRH dramatically increased GH secretion in steers, the peak level after GHRH injection in the present study was smaller than that of Holstein heifers at the corresponding age (6 mo old) shown in the report by Shingu et al. [26]. The difference is

Fig. 4 A: Plasma GH response to intravenous (iv) injection of GHRH alone (closed circles) or in combination with icv injection of melatonin (MEL, $100 \mu \mathrm{g}$, open squares). Closed and open arrows show the time of the icv and iv injections, respectively. B: AUC after icv and iv injections of MEL and GHRH. Each value is expressed as the mean \pm standard errors. The asterisks show the statistical significance compared to the corresponding value of the control (SAL, iv) group (**; $\mathrm{P}<0.01, *$; $\mathrm{P}<0.05$ ).

appeared to be caused by the sexual dimorphism of GH response to GHRH in cattle [1].

The present result raises one possibility that the icv injection of MEL stimulated GH secretion through the hypothalamus. The endogenous MEL, secreted from the pineal gland, is detected not only in the blood but also in the CSF in several species, such as non-human primates [22], sheep [25], goats [11] and cattle [9]. The existence of MEL in the CSF is very important, because MEL from the pineal gland is supposed to enter the CSF through the pineal recess [28], and would reach the peri-3 $\mathrm{V}$ area, especially the hypothalamus, the presumable target site of MEL controlling the reproductive axis in sheep $[16,18]$. At this point of view, the injection of MEL into the $3 \mathrm{~V}$ is an appropriate approach in order to evaluate the contribution of the hypothalamus to the effects of MEL on pituitary hormone secretion. Further- 
more, the injection method into the $3 \mathrm{~V}$ has an advantage over the lateral ventricular injection, because the substances injected into the $3 \mathrm{~V}$ would reach more local area, which is the presumable target of substances injected than those into the lateral ventricle. Definitely, the medial basal hypothalamus has been shown as the binding site of MEL in the bovine brain [3]. In terms of the regulatory mechanism of GH secretion, most of GHRH cells are located in the arcuate nucleus of the bovine hypothalamus [15]. It is possible that the exogenous MEL injected into the $3 \mathrm{~V}$ reached the arcuate nucleus and stimulated GHRH release followed by the increase in GH. However, the present results could not give a solid evidence for this hypothesis. Because the icv injection of MEL into the $3 \mathrm{~V}$ did not alter the $\mathrm{GH}$ response to intravenous GHRH injection (Fig. 4). The involvement of the hypothalamus in MEL-mediated GH secretion has been suggested in several reports. Richardson et al. [23] suggested that MEL stimulated SS release from rat hypothalamic explants. As far as we know, this report is only evidence directly showing the involvement of the hypothalamus in MEL-mediated GH release. Another group reported that MEL administration increased not only basal $\mathrm{GH}$ but also GHRH-induced GH release in humans [29]. They interpreted the result to mean that MEL inhibited SS release at the hypothalamus level.

On the other hand, it has been suggested that MEL acts on the pituitary directly to affect GH secretion. MEL reduced $\mathrm{GH}$ release from GH4 cells [8]. Nonno et al. [20] suggested that MEL receptors were absent or the density of the receptors was extremely low in the bovine hypothalamus. Therefore, we could not exclude the possibility that MEL induces $\mathrm{GH}$ release at the pituitary level. Moreover, it has been reported that ghrelin, an endogenous ligand for the $\mathrm{GH}$ secretagogue that stimulates $\mathrm{GH}$ release, was decreased by MEL treatment [19]. The result suggests that factors other than hypothalamic hormones are involved in the regulation of GH secretion by MEL. Although the effects of MEL on GH secretion has been examined, a consistent understanding has not been obtained to date. Further investigation is required to solve remained questions.

The MEL secretion has a distinct nocturnal rise in cattle $[5,9]$ likewise in other species $[11,13,22]$. It is well known that GH secretion also has a nocturnal increment in humans [7]. Therefore, it was hypothesized that MEL could be involved in the increase in $\mathrm{GH}$ during the night. However, such nocturnal $\mathrm{GH}$ augmentation has not been clearly reported in cattle $[2,14,21]$ so far. Further investigation for the relationship between spontaneous MEL secretion from the pineal gland and the somatotropic axis in this species is necessary.

ACKNOWLEDGEMENTS. We thank the staff of Ruminants and Field Management Section, Department of Research Planning and Coordination, National Institute of Livestock and Grassland Science, Japan, H. Morikawa, S. Nonaka, H. Ito, M. Ito, M. Shiwa and T. Fukiage for their technical assistance. This work was supported in part by a
Grant-in-Aid for Scientific Research (17580251, to EK, SK and MS) from the Japan Society for the Promotion of Science.

\section{REFERENCES}

1. Baumgard, L. H., Weber, W. J., Kazmer, G. W., Zinn, S. A., Hansen, L. B., Chester-Jones, H. and Crooker, B. A. 2002. Effects of selection for milk yield on growth hormone response to growth hormone releasing factor in growing Holstein calves. J. Dairy Sci. 85: 2529-2540.

2. Breier, B. H., Bass, J. J., Butler, J. H. and Gluckman, P. D. 1986. The somatotrophic axis in young steers: influence of nutritional status on pulsatile release of growth hormone and circulating concentrations of insulin-like growth factor $1 . J$. Endocrinol. 111: 209-215.

3. Cardinali, D. P., Vacas, M. I. and Boyer, E. E. 1979. Specific binding of melatonin in bovine brain. Endocrinology 105: 437441.

4. Clarke, I. J. 1992. What can we learn from sampling hypophysial portal blood? Ciba Found. Symp. 168: 87-95; Discussion 95-103.

5. Eriksson, L., Valtonen, M., Laitinen, J. T., Paananen, M. and Kaikkonen, M. 1998. Diurnal rhythm of melatonin in bovine milk: pharmacokinetics of exogenous melatonin in lactating cows and goats. Acta Vet. Scand. 39: 301-310.

6. Etherton, T. D. and Bauman, D. E. 1998. Biology of somatotropin in growth and lactation of domestic animals. Physiol. Rev. 78: 745-761.

7. Finkelstein, J. W., Roffwarg, H. P., Boyar, R. M., Kream, J. and Hellman, L. 1972. Age-related change in the twenty-fourhour spontaneous secretion of growth hormone. J. Clin. Endocrinol. Metab. 35: 665-670.

8. Griffiths, D., Bjoro, T., Gautvik, K. and Haug, E. 1987. Melatonin reduces the production and secretion of prolactin and growth hormone from rat pituitary cells in culture. Acta Physiol. Scand. 131: 43-49.

9. Hedlund, L., Lischko, M. M., Rollag, M. D. and Niswender, G. D. 1977. Melatonin: daily cycle in plasma and cerebrospinal fluid of calves. Science 195: 686-687.

10. Johke, T. 1978. Effects of TRH on circulating growth hormone, prolactin and triiodothyronine levels in the bovine. Endocrinol. Jpn. 25: 19-26.

11. Kanematsu, N., Mori, Y., Hayashi, S. and Hoshino, K. 1989. Presence of a distinct 24-hour melatonin rhythm in the ventricular cerebrospinal fluid of the goat. J. Pineal Res. 7: 143-152.

12. Kasuya, E., Sakumoto, R., Saito, T., Ishikawa, H., Sengoku, H., Nemoto, T. and Hodate, K. 2005. A novel stereotaxic approach to the hypothalamus for the use of push-pull perfusion cannula in Holstein calves. J. Neurosci. Methods 141: $115-124$

13. Kostoglou-Athanassiou, I., Treacher, D. F., Wheeler, M. J. and Forsling, M. L. 1998. Melatonin administration and pituitary hormone secretion. Clin. Endocrinol. (Oxf.) 48: 31-37.

14. Lee, C. Y., Hunt, D. W., Gray, S. L. and Henricks, D. M. 1991. Secretory patterns of growth hormone and insulin-like growth factor-I during peripubertal period in intact and castrate male cattle. Domest. Anim. Endocrinol. 8: 481-489.

15. Leshin, L. S., Barb, C. R., Kiser, T. E., Rampacek, G. B. and Kraeling, R. R. 1994. Growth hormone-releasing hormone and somatostatin neurons within the porcine and bovine hypothalamus. Neuroendocrinology 59: 251-264. 
16. Lincoln, G. A. and Maeda, K. I. 1992. Reproductive effects of placing micro-implants of melatonin in the mediobasal hypothalamus and preoptic area in rams. J. Endocrinol. 132: 201215.

17. Lisoni, P., Resentini, M., Mauri, R., De Medici, C., Morabito, F., Esposti, D., Di Bella, L., Esposti, G., Rossi, D. and Parravicini, L. 1986. Effect of an acute injection of melatonin on the basal secretion of hypophyseal hormones in prepubertal and pubertal healthy subjects. Acta Endocrinol. (Copenh.) 111: 305-311.

18. Malpaux, B., Daveau, A., Maurice-Mandon, F., Duarte, G. and Chemineau, P. 1998. Evidence that melatonin acts in the premammillary hypothalamic area to control reproduction in the ewe: presence of binding sites and stimulation of luteinizing hormone secretion by in situ microimplant delivery. Endocrinology 139: 1508-1516.

19. Mustonen, A. M., Nieminen, P. and Hyvarinen, H. 2001. Preliminary evidence that pharmacologic melatonin treatment decreases rat ghrelin levels. Endocrine 16: 43-46.

20. Nonno, R., Capsoni, S., Lucini, V., Moller, M., Fraschini, F. and Stankov, B. 1995. Distribution and characterization of the melatonin receptors in the hypothalamus and pituitary gland of three domestic ungulates. J. Pineal Res. 18: 207-216.

21. Ozawa, A., Hodate, K., Miyamoto, S., Ohtani, F., Tsushima, T. and Johke, T. 1991. Plasma profiles of insulin-like growth factor-I for 24 hours and after injection of bovine growth hormone in dairy heifers. Anim. Sci. Technol. (Jpn.) 62: 933-938.

22. Reppert, S. M., Perlow, M. J., Tamarkin, L. and Klein, D. C. 1979. A diurnal melatonin rhythm in primate cerebrospinal fluid. Endocrinology 104: 295-301.

23. Richardson, S. B., Hollander, C. S., Prasad, J. A. and Hirooka, Y. 1981. Somatostatin release from rat hypothalamus in vitro: effects of melatonin and serotonin. Endocrinology 109: 602-
606.

24. Saito, T., Nemoto, T., Nagase, Y., Kasuya, E. and Sakumoto, R. 2004. Development of a stereotaxic instrument for study of the bovine central nervous system. Brain Res. Bull. 62: 369377.

25. Shaw, P. F., Kennaway, D. J. and Seamark, R. F. 1989. Evidence of high concentrations of melatonin in lateral ventricular cerebrospinal fluid of sheep. J. Pineal Res. 6: 201-208.

26. Shingu, H., Hodate, K., Kushibiki, S., Ueda, Y., Watanabe, A., Shinoda, M. and Matsumoto, M. 2001. Profiles of growth hormone and insulin secretion, and glucose response to insulin in growing Japanese Black heifers (beef type): comparison with Holstein heifers (dairy type). Comp. Biochem. Physiol. C Toxicol. Pharmacol. 130: 259-270.

27. Smythe, G. A. and Lazarus, L. 1974. Growth hormone responses to melatonin in man. Science 184: 1373-1374.

28. Tricoire, H., Locatelli, A., Chemineau, P. and Malpaux, B. 2002. Melatonin enters the cerebrospinal fluid through the pineal recess. Endocrinology 143: 84-90.

29. Valcavi, R., Zini, M., Maestroni, G. J., Conti, A. and Portioli, I. 1993. Melatonin stimulates growth hormone secretion through pathways other than the growth hormone-releasing hormone. Clin. Endocrinol. (Oxf.) 39: 193-199.

30. Valcavi, R., Dieguez, C., Azzarito, C., Edwards, C. A., Dotti, C., Page, M. D., Portioli, I. and Scanlon, M. F. 1987. Effect of oral administration of melatonin on GH responses to GRF 1-44 in normal subjects. Clin. Endocrinol. (Oxf.) 26: 453-458.

31. Waldhauser, F., Lieberman, H. R., Lynch, H. J., Waldhauer, M., Herkner, K., Frisch, H., Vierhapper, H., Waldhausl, W., Schemper, M., Wurtman, R. J. and Crowley, W. F. 1987. A pharmacological dose of melatonin increases PRL levels in males without altering those of GH, LH, FSH, TSH, testosterone or cortisol. Neuroendocrinology 46: 125-130. 